\title{
Canadian guidelines for colorectal cancer screening
}

\author{
Jennifer J Telford MD MPH FRCPC, Medical Director Colon Check
}

$\mathrm{T}$ he recent position statement from the Canadian Association of Gastroenterology (CAG) on colorectal cancer screening (1) updates the CAG's previously published guidelines (2). The position statement addresses the following: opportunistic versus programmatic screening; the fecal immunochemical test (FIT); new evidence for flexible sigmoidoscopy; the current American recommendations for colorectal cancer screening; and quality improvement. The statement focuses on average-risk screening, and does not incorporate screening of individuals with a family history of colorectal neoplasia nor surveillance of individuals following endoscopic or surgical treatment of colorectal neoplasia.

Colorectal cancer screening can be divided into opportunistic and programmatic. Until recently, opportunistic colorectal cancer screening was the only option available to Canadians. However, over the past five years, all Canadian provinces have been developing or have implemented programmatic population-based screening programs using a fecal occult blood test - either guaiac or immunochemical - as the primary screening test with colonoscopic follow-up of positive tests (Table 1) (3). Most of the screening programs do not distinguish the presence of a family history of colorectal cancer, and treat all incoming participants as 'average risk'. Individuals 50 to 75 years of age are eligible to participate.

To date, there are no published data comparing programmatic screening with opportunistic screening and, in most jurisdictions, the two approaches operate in parallel (4). Programmatic colorectal cancer screening should provide equal access to eligible citizens, ensure screening or surveillance is conducted at appropriate intervals, provide follow-up colonoscopy in a timely manner, assure quality, and monitor outcomes to document that the impact of programmatic screening on colorectal cancer mortality and incidence justifies the cost.

The CAG position statement recommends the FIT at an interval of at least every two years as the test of choice for programmatic screening. While there is no evidence regarding repeated FIT, most experts are comfortable extrapolating the data from guaiac fecal occult blood tests (5-9) and expect, given the favourable test performance characteristics of FIT (10-13), a larger mortality benefit. The advantages of FIT over the guaiac test include fewer stool specimens, no dietary or medication restrictions, automation, increased detection of colorectal cancer, increased detection of adenomas and increased participation $(11,14)$. The disadvantages of FIT are the increased cost and test instability at different temperatures (15) and over time (16). Since 2008, 13 brands of FIT have become available in Canada, and the sensitivity for the detection of colorectal cancer will vary depending on the test used. The best FIT has yet to be determined, but may differ depending on jurisdiction. For example, a test that demonstrates stability at extreme temperatures would be a desirable feature that would facilitate test transportation in Canada.

Flexible sigmoidoscopy every 10 years was the other strategy recommended in the position statement for programmatic screening of colorectal cancer. This recommendation is based on the multicentre randomized controlled trial of a single flexible sigmoidoscopy between 55 and 64 years of age (17). The group that was randomly assigned to
TABLE 1

Status of provincial colorectal cancer screening programs*

\begin{tabular}{lll}
\hline Province & $\begin{array}{l}\text { Status of } \\
\text { screening program }\end{array}$ & $\begin{array}{l}\text { Primary } \\
\text { screening test }\end{array}$ \\
\hline Newfoundland and Labrador & Planning & FIT \\
New Brunswick & Planning & FIT \\
Prince Edward Island & Province wide & FIT \\
Nova Scotia & Province wide & FIT \\
Quebec & Phased rollout & FIT \\
Ontario & Province wide & Guaiac FOBT
\end{tabular}

(considering FIT pilot)

Manitoba

Saskatchewan

Alberta

(FIT pilot planned)

Phased rollout

Guaiac FOBT

Phased rollout FIT

Phased rollout Guaiac FOBT

British Columbia

Phased rollout

FIT

*The status of colorectal cancer screening programs in the territories is not known. FIT Fecal immunochemical test; FOBT Fecal occult blood test

flexible sigmoidoscopy demonstrated a significant reduction in colorectal cancer incidence and mortality that persisted through the 11 years of follow-up. There was also a decrease in all-cause mortality in the screened group, but this was not statistically significant. The CAG position paper suggests that the provincial screening programs should consider flexible sigmoidoscopy, but it is unclear whether they intend flexible sigmoidoscopy to be combined with fecal occult blood testing as previously recommended (2) or in place of fecal occult blood testing. Studies assessing combined flexible sigmoidoscopy and low sensitivity guaiac fecal occult blood testing support the use of flexible sigmoidoscopy alone (18-20). There are no data assessing high-sensitivity guaiac fecal occult blood testing or FIT combined with flexible sigmoidoscopy. Despite this lack of evidence, a combination of the two tests has been a recommended strategy in published guidelines (21).

The majority of Canadians are undergoing colorectal cancer screening in an opportunistic manner, and a proportion may elect to continue with opportunistic screening even once programmatic screening is fully developed. In the CAG position paper, the following strategies were deemed appropriate for opportunistic colorectal cancer screening: annual or biennial FIT, flexible sigmoidoscopy every 10 years and colonoscopy every 10 years. Fecal DNA testing, computed tomography $(\mathrm{CT})$ colonography, and double-contrast barium enema are not recommended for either programmatic or opportunistic colorectal cancer screening.

The CAG position statement is similar to the US Preventive Services Task Force (21) and American College of Gastroenterology (22) recommendations, but differs from the US Multi-Society Task Force (23) by excluding fecal DNA testing and CT colonography. Furthermore, in the American recommendations, flexible sigmoidoscopy is recommended at an interval of every five years; however, these recommendations

Department of Gastroenterology, St Paul's Hospital, University of British Columbia, Vancouver, British Columbia

Correspondence: Dr Jennifer J Telford, Department of Gastroenterology, St Paul's Hospital, Pacific Gastroenterology Associates, 770-1190 Hornby Street,

Vancouver, British Columbia V6Z 2K5. Telephone 604-688-6332 ext 222, fax 604-689-2004, e-mail jtelford@telus.net

Received for publication July 18, 2011. Accepted July 25, 2011 
were published before the landmark study by Atkin et al (17) discussed above. Presently, fecal DNA testing is not available in Canada and is not cost effective when compared with other strategies $(24,25)$. On the other hand, CT colonography is widely available but is limited by a low sensitivity for the detection of multiple polyps smaller than $6 \mathrm{~mm}$ in size (26). Adenoma multiplicity - more than size or high-risk histology - is associated with the presence of advanced adenomas or invasive cancer at surveillance colonoscopy (27). The short screening interval of three to five years, and the need for follow-up colonoscopy and polypectomy increases the cost of CT colonography.

Colonoscopy is the most sensitive test available for detecting colorectal cancer and colorectal adenomas. Two randomized controlled trials evaluating the effect of colonoscopy on colorectal cancer incidence and mortality are currently recruiting in Europe (NCT01014039 and NCT00883792), as well as a randomized trial comparing FIT with colonoscopy (NCT00906997). Case-control studies have shown that colonoscopy can decrease colorectal cancer mortality and incidence (28). However, we have become well aware that colonoscopy is not perfect $(29,30)$, and that endoscopist technique is strongly associated with missed colorectal adenomas and interval cancers (31-33). Colonoscopy is a common test for primary colorectal cancer screening, and is the standard of care for follow-up of an abnormal fecal occult blood test or a flexible sigmoidoscopy. Therefore, it is imperative that any colorectal cancer screening program ensures high-quality colonoscopy. There is no reason why this cannot be achieved with education and, if necessary, additional training. The Quality Program - Endoscopy (www.cag-acg.org) incorporates a physician practice audit (http://cag.medicalconsensus.org) and the Global

\section{REFERENCES}

1. Leddin DJ, Enns R, Hilsden R, et al. Canadian Association of Gastroenterology position statement on screening individuals at average risk for developing colorectal cancer: 2010. Can J Gastroenterol 2010;24:705-14.

2. Leddin D, Hunt R, Champion M, et al. Canadian Association of Gastroenterology and the Canadian Digestive Health Foundation: Guidelines on colon cancer screening. Can J Gastroenterol 2004;18:93-9.

3. Colorectal Cancer Screening. <www.cancerview.ca/idc/groups/ public/documents/webcontent/screen_colorec_elements_dec10.pdf $>$ (Accessed on June 3, 2011).

4. Madlensky L, McLaughlin J, Goel V. A comparison of self-reported colorectal cancer screening with medical records. Cancer Epidemiol Biomarkers Prev 2003;12:656-9.

5. Mandel JS, Bond JH, Church TR, et al. Reducing mortality from colorectal cancer by screening for fecal occult blood. Minnesota Colon Cancer Control Study. N Engl J Med 1993;328:1365-71.

6. Mandel JS, Church TR, Bond JH, et al. The effect of fecal occult blood screening on the incidence of colorectal cancer. N Engl J Med 2000;343:1603-7.

7. Kronborg O, Fenger C, Olsen J, Jorgensen OD, Sondergaard O. Randomised study of screening for colorectal cancer with faecal-occult-blood test. Lancet 1996;348:1467-71.

8. Jorgensen OD, Kronborg O, Fenger C. A randomised study of screening for colorectal cancer using faecal occult blood testing: Results after 13 years and seven biennial screening rounds. Gut 2002;50:29-32.

9. Hardcastle JD, Chamberlain JO, Robinson MH, et al. Randomised controlled trial of faecal-occult-blood screening for colorectal cancer. Lancet 1996;348:1472-7.

10. Hol L, van Leerdam ME, van Ballegooijen M, et al. Screening for colorectal cancer: Randomised trial comparing guaiac-based and immunochemical faecal occult blood testing and flexible sigmoidoscopy. Gut 2010;59:62-8.

11. van Rossum LG, van Rijn AF, Laheij RJ, et al. Random comparison of guaiac and immunochemical fecal occult blood tests for colorectal cancer in a screening population. Gastroenterology 2008;135:82-90.

12. Allison JE, Sakoda LC, Levin TR, et al. Screening for colorectal neoplasms with new fecal occult blood tests: update on performance characteristics. J Natl Cancer Inst 2007;99:1462-70.
Rating Scale (http://ca.globalratingscale.com) - a biannual survey developed in the United Kingdom to assess quality in the endoscopy unit from the patient's perspective. Other resources adapted from the United Kingdom include directly observed procedural skills used to evaluate trainees and practicing endoscopists, as well as the 'Train the Trainer' colonoscopy courses. Presently, the missing piece is resources for practicing endoscopists to improve their colonoscopy and polypectomy technique. CAG has been the leader in colonoscopy quality improvement, and I hope the Association will develop courses for endoscopists to upgrade their colonoscopy skills. This would be an invaluable resource to colorectal cancer screening in Canada, and I anticipate that we would see a 'spillover' effect with improvement in the quality of endoscopy services overall.

\section{SUMMARY}

Decisions regarding colorectal cancer screening will continue to depend on local resources, which in some jurisdictions includes programmatic screening and individual patient preferences. I encourage gastroenterologists to participate in programmatic screening and assist in developing the colonoscopy quality assurance and improvement programs. Our involvement would ensure that we remain leaders in this area and that our expertise in quality in endoscopy is recognized. Finally, participation in programmatic screening should benefit endoscopic services by increasing resources to support higher colonoscopy volumes, shorter wait lists and continuing quality assurance.
13. Park DI, Ryu S, Kim YH, et al. Comparison of guaiac-based and quantitative immunochemical fecal occult blood testing in a population at average risk undergoing colorectal cancer screening. Am J Gastroenterol 2010;105:2017-25.

14. Hoffman RM, Steel S, Yee EF, Massie L, Schrader RM, Murata GH. Colorectal cancer screening adherence is higher with fecal immunochemical tests than guaiac-based fecal occult blood tests: A randomized, controlled trial. Prev Med 2010;50:297-9.

15. Grazzini G, Ventura L, Zappa M, et al. Influence of seasonal variations in ambient temperatures on performance of immunochemical faecal occult blood test for colorectal cancer screening: Observational study from the Florence district. Gut 2010;59:1511-5.

16. van Rossum LG, van Rijn AF, Laheij RJ, et al. Cutoff value determines the performance of a semi-quantitative immunochemical faecal occult blood test in a colorectal cancer screening programme. Br J Cancer 2009;101:1274-81.

17. Atkin WS, Edwards R, Kralj-Hans I, et al. Once-only flexible sigmoidoscopy screening in prevention of colorectal cancer: A multicentre randomised controlled trial. Lancet 2010;375:1624-33.

18. Lieberman DA, Weiss DG. One-time screening for colorectal cancer with combined fecal occult-blood testing and examination of the distal colon. N Engl J Med 2001;345:555-60.

19. Rasmussen M, Kronborg O, Fenger C, Jorgensen OD. Possible advantages and drawbacks of adding flexible sigmoidoscopy to hemoccult-II in screening for colorectal cancer. A randomized study. Scand J Gastroenterol 1999;34:73-8.

20. Berry DP, Clarke P, Hardcastle JD, Vellacott KD. Randomized trial of the addition of flexible sigmoidoscopy to faecal occult blood testing for colorectal neoplasia population screening. Br J Surg 1997;84:1274-6.

21. Screening for colorectal cancer: U.S. Preventive Services Task Force recommendation statement. Ann Intern Med 2008;149:627-37.

22. Rex DK, Johnson DA, Anderson JC, Schoenfeld PS, Burke CA, Inadomi JM. American College of Gastroenterology guidelines for colorectal cancer screening 2009 [corrected]. Am J Gastroenterol 2009;104:739-50.

23. Levin B, Lieberman DA, McFarland B, et al. Screening and surveillance for the early detection of colorectal cancer and 
adenomatous polyps, 2008: A joint guideline from the American Cancer Society, the US Multi-Society Task Force on Colorectal Cancer, and the American College of Radiology. Gastroenterology 2008;134:1570-95.

24. Parekh M, Fendrick AM, Ladabaum U. As tests evolve and costs of cancer care rise: Reappraising stool-based screening for colorectal neoplasia. Aliment Pharmacol Ther 2008;27:697-712.

25. Telford JJ, Levy AR, Sambrook JC, Zou D, Enns RA.

The cost-effectiveness of screening for colorectal cancer. CMAJ 2010;182:1307-13.

26. Rex DK, Overhiser AJ, Chen SC, Cummings OW, Ulbright TM. Estimation of impact of American College of Radiology recommendations on CT colonography reporting for resection of high-risk adenoma findings. Am J Gastroenterol 2009;104:149-53.

27. Winawer SJ, Zauber AG, Fletcher RH, et al. Guidelines for colonoscopy surveillance after polypectomy: A consensus update by the US Multi-Society Task Force on Colorectal Cancer and the American Cancer Society. Gastroenterology 2006;130:1872-85.
28. Winawer SJ, Zauber AG, Ho MN, et al. Prevention of colorectal cancer by colonoscopic polypectomy. The National Polyp Study Workgroup. N Engl J Med 1993;329:1977-81.

29. Baxter NN, Goldwasser MA, Paszat LF, Saskin R, Urbach DR, Rabeneck L. Association of colonoscopy and death from colorectal cancer. Ann Intern Med 2009;150:1-8.

30. Singh H, Nugent Z, Demers AA, Bernstein CN. Rate and predictors of early/missed colorectal cancers after colonoscopy in Manitoba: A population-based study. Am J Gastroenterol 2010;105:2588-96.

31. Barclay RL, Vicari JJ, Doughty AS, Johanson JF, Greenlaw RL. Colonoscopic withdrawal times and adenoma detection during screening colonoscopy. N Engl J Med 2006;355:2533-41.

32. Kaminski MF, Regula J, Kraszewska E, et al. Quality indicators for colonoscopy and the risk of interval cancer. N Engl J Med 2010;362:1795-803.

33. Chen SC, Rex DK. Endoscopist can be more powerful than age and male gender in predicting adenoma detection at colonoscopy. Am J Gastroenterol 2007;102:856-61. 


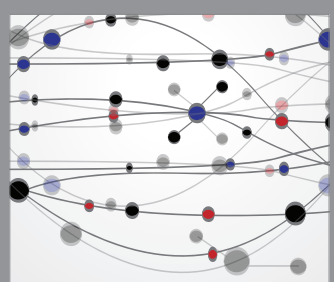

The Scientific World Journal
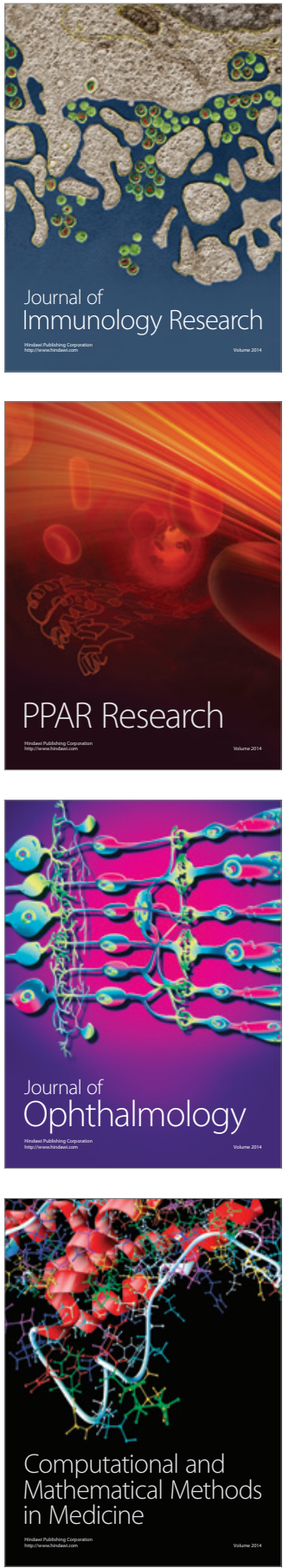

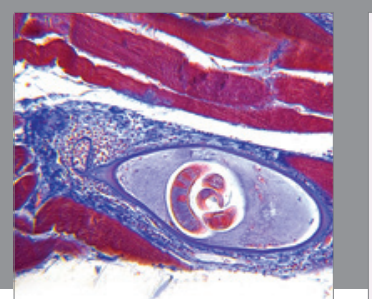

Gastroenterology Research and Practice

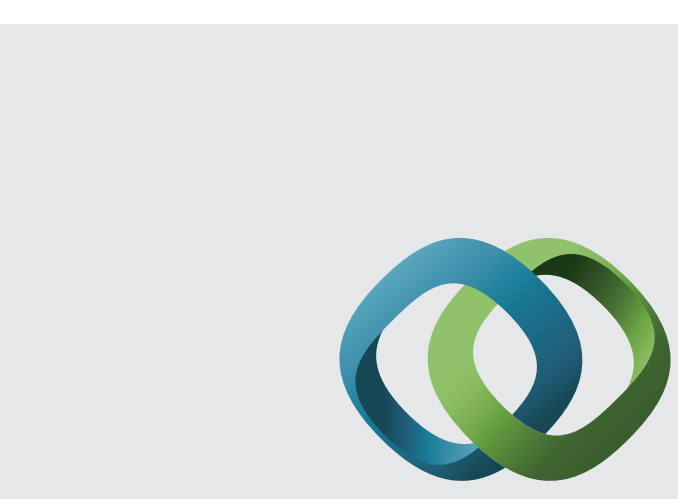

\section{Hindawi}

Submit your manuscripts at

http://www.hindawi.com
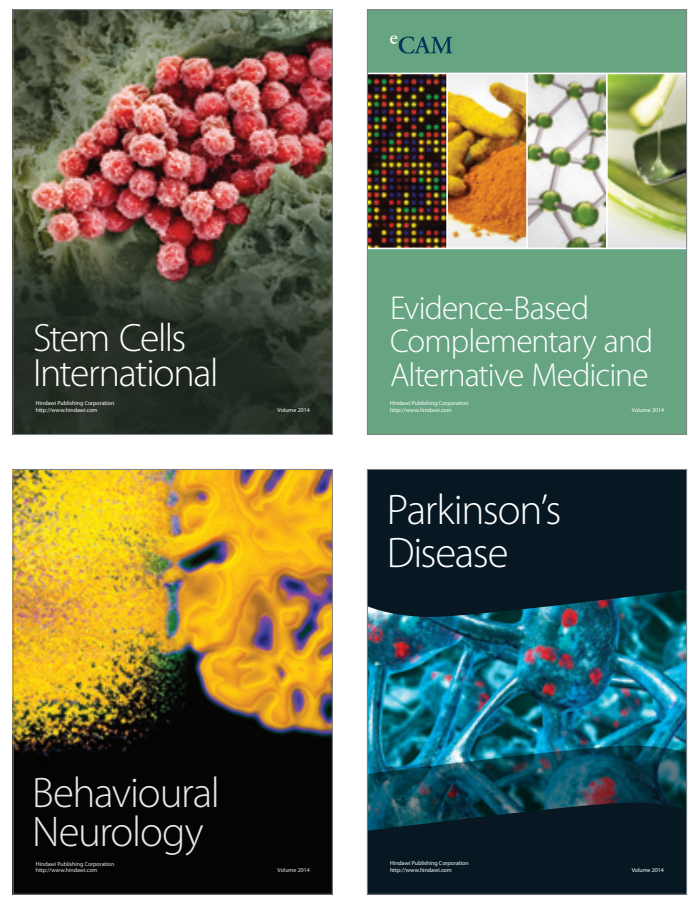
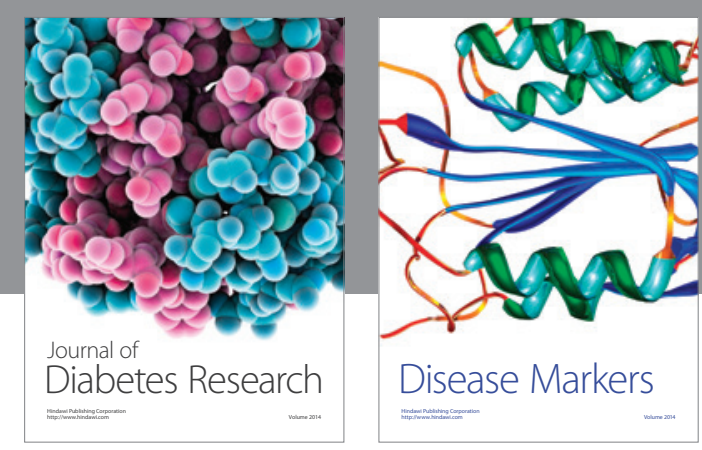

Disease Markers
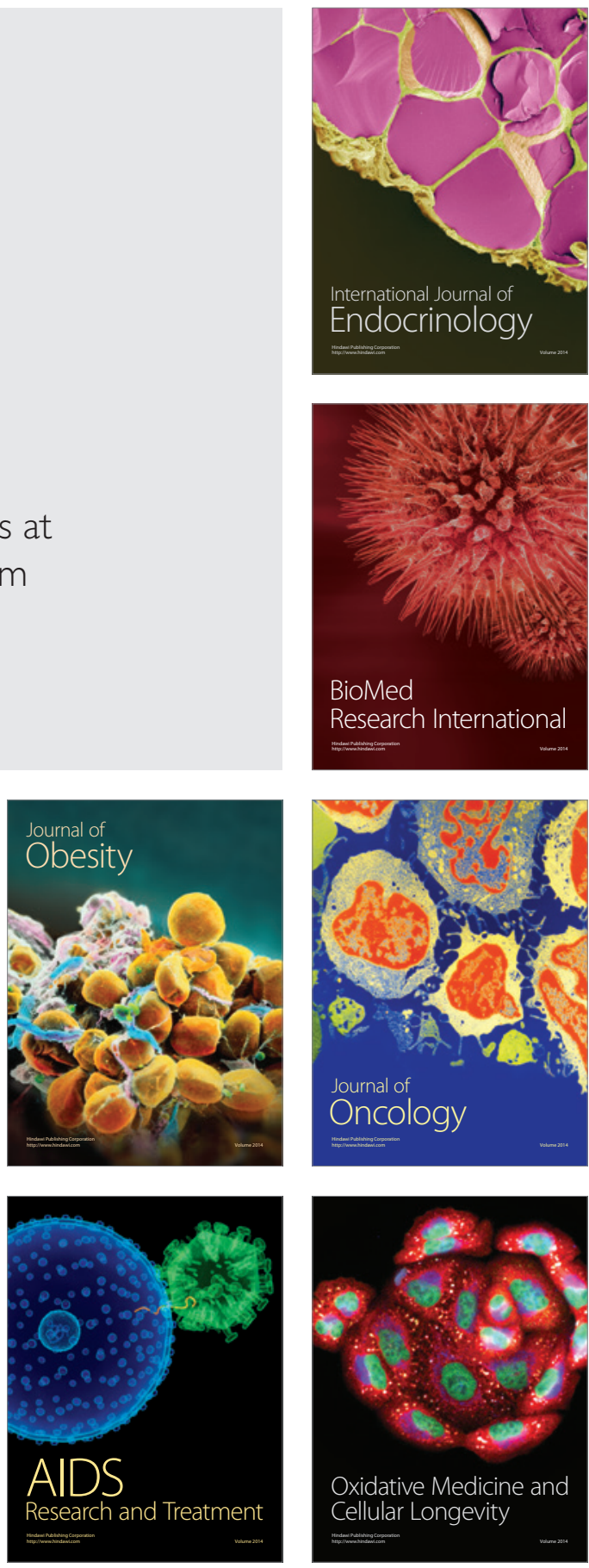